Original Article

\title{
Factors affecting the interest of rehabilitation professionals indirectly supporting preventive care projects
}

\author{
Yoshio Suzuki, RPT1)*, Reiko IshiYama, $\mathrm{PhD}^{2)}$ \\ 1) Doctoral Program in Health Sciences, International University of Health and Welfare: 4-1-6 \\ Akasaka, Minato-ku, Tokyo 107-8402, Japan \\ 2) Graduate School, Department of Health and Welfare Management, International University of \\ Health and Welfare, Japan
}

\begin{abstract}
Purpose] To identify the factors affecting the interest of rehabilitation professionals who indirectly support preventive care projects. [Participants and Methods] Rehabilitation professionals (physical therapists, occupational therapists, and speech-language-hearing therapists) working in 617 hospitals and other health facilities in A Prefecture, Japan. On the basis of their degree of interest in the activities of their respective preventive care projects, the professionals were classified into three groups after evaluating their responses to a self-reporting questionnaire (1,851 parts in total). The subsequent comparisons were performed among the three groups and their responses to the remaining questions. [Results] Analysis of the responses provided by 354 of the 374 rehabilitation professionals who answered the questionnaire revealed the following factors affecting their degree of interest in the preventive care projects indirectly supported by them: advanced age; abundant years of experience practicing; being speech-language-hearing-therapists; experience in post-graduate training; and considering the scope of support as a part of the community. Furthermore, the vast majority of individuals in the group showing superior interest had experience in activities related to indirect support. [Conclusion] Confirmation of the extent to which indirect support by rehabilitation professionals is effective for preventive care services is essential, since such support is difficult to demonstrate, unlike direct support.

Key words: Preventive care project, Indirect support, Rehabilitation professionals
\end{abstract}

(This article was submitted Apr. 26, 2021, and was accepted Jun. 6, 2021)

\section{INTRODUCTION}

Thus far, the contents of conventional preventive care for disability implemented by municipalities (preventive care projects) have been biased toward approaches of functional recovery focusing mainly on the physical functions of the elderly ${ }^{1)}$. In addition, it has been underlined that even though the number of elderly participating in such projects did not expand, preventive care projects remain inefficient for motives like channeling most of the project expenses only for the elderly who are eligible for the service in Japan²).

Based on these issues, the long-term care insurance system (LTCI) was revised in 2015, in the context of which designs of preventive care projects were also adjusted ${ }^{3)}$. Moreover, the renewed total project for care prevention/daily living support, "SOGO JIGYO", appeared as a new business system by the Ministry of Health, Labour and Welfare of Japan (MHLW) ${ }^{4}$. Accordingly, the importance of not only supporting the physical function improvement of community-dwelling elderly but also of providing unbiased support is accentuated. In this sense, the aforementioned project includes approaches to their specific environment, such as support for the development of healthier lifestyles and roles in their community ${ }^{5}$.

*Corresponding author. Yoshio Suzuki (E-mail: 21s3020@g.iuhw.ac.jp)

(C2021 The Society of Physical Therapy Science. Published by IPEC Inc.

(c) $(-)$ This is an open-access article distributed under the terms of the Creative Commons Attribution Non-Commercial No Deriva-

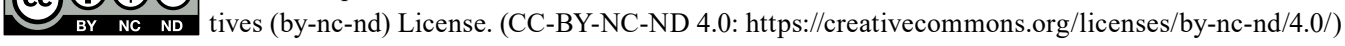


Regarding the involvement of rehabilitation professionals in preventive care projects, expectations falling upon their active participation in the community have been increasing, presumably due to the current establishment of "community-based rehabilitation support projects"6). However, when said professionals turned their attention to the intervention effect of care projects, it was concluded that although reports on this subject existed in the former preventive care projects ${ }^{7,8)}$, they were centered on physical functions; besides the effects of their intercession had hardly been verified through indicators other than motor function ${ }^{9}$.

In the 2015 Community Health Comprehensive Project, "Research on the promotion of community health activities and grasp of actual conditions of physical therapists and occupational therapists belonging to local governments", the concept of activities combining individual support, community support, direct approach, and indirect approach was illustrated, portraying how physical therapists or occupational therapists employed by local governments could engage with communitydwelling elderly ${ }^{10,11)}$.

Additionally, it has been reinforced that the activity of rehabilitation workers in the region of interest in the future should ideally entail community support as well as an indirect approach ${ }^{12}$. Furthermore, in a set of community rehabilitation activities, it seems essential not only to directly engage with community-dwelling elderly by centering conventional classroomtype exercise and gymnastics guidance, but also to encourage the elderly living in the area to participate in community activities independently while making use of local amenities and human and social resources ${ }^{13}$.

Nevertheless, we verified a lack of reports referring to the activities of rehabilitation professionals in the community through indirect support, and in particular, there are almost none that investigate the degree of interest of individuals working in rehabilitation. Therefore, with this study our purpose was to better explore how cited professionals are involved in supporting community-dwelling elderly in preventive care projects originating from municipalities to find out if the degree of interest in indirect support relates to attribute information and attitude toward work and elderly support. In other words, we intended to reveal some of the factors that affect the degree of personal interest of rehabilitation professionals in the context of indirect support such as Advising and supporting organizers and leaders in the field.

\section{PARTICIPANTS AND METHODS}

This study was cross-sectional study using self-administered independent questionnaire.

The participants of this study were physical therapists (PT), occupational therapists (OT), and speech-language-hearing therapists (ST) who are working at hospitals, other health facilities, offices, etc. in A Prefecture. This study was approved by the Ethics Review Committee of the International University of Health and Welfare (approval number 19-Ig-15). Moreover, since the responses requested were to anonymous questionnaires, it was clearly stated in the attached explanation document that consent was given by answering and returning the survey.

We designed a survey composed of several questionnaires. This was conducted with rehabilitation professionals to understand how they deal with indirect support for community-dwelling elderly, after which the responses obtained were summarized and analyzed.

Survey procedure, as of October 1, 2019, was elucidated to the person in charge of rehabilitation departments of the targeted professionals (in hospitals, geriatric health facilities, geriatric welfare facilities, facilities for the elderly, child welfare facilities, public offices, educational institutions, etc., totaling 617 facilities) and disclosed on the homepage of rehabilitation professional organizations in A Prefecture. More precisely, a research request form (1 part), the instructions (1 part), a consent form ( 1 part), and 3 questionnaires (1,851 persons) were mailed, and rehabilitation professionals at these respective facilities, as of January 2020, responded randomly, after which the surveys were individually enclosed and returned to their envelopes and were collected from January to February 2020. Consequently, we analyzed 354 from 374 people who answered at 125 facilities (recovery rate of $20.0 \%$ ), excluding 20 people who had not responded to the survey items associated with the degree of interest in preventive care projects.

The investigated topics encompassed attributes such as age, occupation, affiliation, career change history, and whether or not there was a training history, and similarly information on personal interests and attitude as a rehabilitation professional, for example, the relevance in business and the subjective way of thinking about elderly support (Table 1). Then, it was considered whether actual professional experience was present, based on 11 items of different activities linked to municipal preventive care projects. Additionally, from the 11 example activities, they were also asked to select up to three that they thought to be of interest and priority. Activities from the 1st to the 4th of the total 11 were associated with direct support, whereas those from 5 th to 11 th were activities in the scope of indirect support (Table 1). All the activity examples were chosen grounded on previous research and materials from MHLW ${ }^{12,14,15)}$.

Regarding the analysis of the collected questionnaires, the following procedure was adopted. Basic statistics were aggregated for each question item of the survey, and this data was used to classify the participants among three groups, which was according to their defined degree of interest in the activities of preventive care projects.

The classification method used for characterizing professionals was the following: professionals belonged to a "group that is interested in indirect support", if all items they chose were items connected to indirect support; if all selected items were related to direct support, they belonged to a "group that is interested in direct support", and otherwise, it was a case of "group interested in both direct and indirect support". 
Table 1. Content of the questionnaires

(1) Basic information of participants

-Age, Number of years of experience, Gender, Occupation (PT / OT / ST)

- Affiliation (acute phase hospital / convtricted hospital / community comprehensive care ward, hospital bed palliative care ward, hospital bed / general hospital / clinic / nursing care elderly health facility / visiting nursing station / day service / day care / nursing care elderly welfare facility / welfare facility for the disabled / others)

Job title (no job title/chief, deputy chief/section chief, head of department, manager, engineer director, etc./others)

- Whether the current address is a municipality where the workplace is located (in/outside the city)

-Whether you have experience in changing jobs or changing positions as a rehabilitation professional

-Whether or not students have attended lectures on preventive care and community-based rehabilitation at a training school

-Whether or not you have taken training on preventive care and community-based rehabilitation since graduating from your training school

(2) The idea of rehabilitation work

-13 items that are used carried out in rehabiritation work * Answers by 4 methods of "always implemented", "sometimes implemented", "not implemented much", and "not implemented at all", respectively

(3) Support for the elderly

-What do you think is the scope of "responsibility" as a rehabilitation professional?

(Until the end of the day's treatment / Until individual issues such as improving walking (transfer) ability, improving changing ability to operate, improving food form, etc. are achieved / until transfer, transfer, discharge or discharge / until indoor life (after discharge/ discharge) / (after discharge / discharge) to living outdoors or in the area / (until social activities including participation in places of communication in the area (after discharge and discharge))

-What do you think is the scope of "support" as a rehabilitation professional?

(Patients and users in charge/ Patients in charge, users and their families/ Patients and users in charge and staff of hospitals and facilities that support them / Entire elderly people in the community / Organizations and activities to support the elderly in the community and the entire person involved)

-When the patient or user in charge leaves or leaves the hospital at home, have you ever been troubled by the fact that there are no resources such as community-based salon?

("Very" / "So-so" / "Rare" / "Not at all")

- Are you interested in the content of care management for patients and users in charge?

("Very" / "So-so" / "Not much" / "Not at all")

(4) Activities as a rehabilitation professional in preventive care projects conducted by municipalities

- Whether or not there is actual activity experience in 11 activity examples

- Selection of activities that you are interested in and think should be prioritized in 11 activity examples (up to 3)

(Item: Activities to guide exercise and gymnastics to residents / Activities as lecturers such as preventive care classes and health courses for residents / Activities as a measuring person such as physical fitness measurement meetings / Activities as implementers of short-term intensive programs * Or more, items related to direct support / Activities to advise and support organizers and leaders in resident-led classrooms / Activities to train resident volunteers/ Activities to promote support among residents / Participation in community-based care conferences / Activities to advise and support administrative staff and community comprehensive support center staff / Activities to advise and support care managers / Activities to provide advice and support to staff at nursing care facilities, etc.) * Items related to indirect support

() are selected.

At that point, the average value and number of degrees were cross-aggregated for each of the groups, and the answered items were compared among the groups. Statistical analysis was attained by the Kruskal-Wallis test for the comparison of age and experience years, and the $\chi^{2}$ test for the comparison of other items. Statistical software SPSS Statistics ver.26 was used for statistical processing; the significance level considered was less than $5 \%$.

As a final note of significance, "indirect support" was defined here, from a previous research, as the "support for residents to independently develop their community through advice, etc., rather than activities of direct approach, mainly by teaching lectures and gymnastics to residents and objects".

\section{RESULTS}

There were 354 questionnaire responses. The overall average age ( \pm SD) of participants was $34.95( \pm 8.3)$, the number of years of experience $( \pm \mathrm{SD})$ was $10.43( \pm 6.9)$, and among the population, 219 were male $(61.9 \%)$ and 135 female $(38.1 \%)$; 260 were PT $(73.4 \%), 66$ were OT $(18.6 \%)$, and 28 were ST $(8.0 \%)$. Classification by the degree of interest resulted in 97 
persons $(27.4 \%)$ in the group with high interest in indirect support, 51 individuals (14.4\%) interested in direct support, and $206(58.2 \%)$ in both indirect and direct support.

Tables 2-5 focuses on the comparison between the three groups with regards to their answers to each item. As a result of this comparison, age, and years of experience were noticed as significantly superior in the group with high interest in indirect support (Kruskal-Wallis test, $\mathrm{p}<0.01)$, equivalent to the number of female professionals $\left(\chi^{2}=8.60, \mathrm{df}=2, \mathrm{p}<0.05\right)$, people that were ST $\left(\chi^{2}=22.34, \mathrm{df}=4, \mathrm{p}<0.01\right)$, people with job titles $\left(\chi^{2}=20.96, \mathrm{df}=6, \mathrm{p}<0.01\right)$, people with experience in changing jobs $\left(\chi^{2}=6.69, \mathrm{df}=2, \mathrm{p}<0.05\right)$ and those who had experience in community-based rehabilitation or nursing care prevention services after graduating from school $\left(\chi^{2}=9.89, \mathrm{df}=2, \mathrm{p}<0.01\right)$ (Table 2$)$. Contrarily, being of lower age, having fewer years of experience, being a male, having no job title, and being a PT all correlated with a high interest in direct support (Table 2).

In addition, factors linked to high interest in indirect support was also determined by cooperation with other regional entities $\left(\chi^{2}=35.83, \mathrm{df}=6, \mathrm{p}<0.01\right)$, and always grasping the characteristics and resources of the corresponding community $\left(\chi^{2}=12.98, \mathrm{df}=6, \mathrm{p}<0.05\right)$. The scope of support was generally considered to be the organization and activities supporting the elderly, both in the community and as an entire person involved in it $\left(\chi^{2}=28.16, \mathrm{df}=8, \mathrm{p}<0.01\right)$ to which several hindrances were underlined around the lack of resources, such as the community-based salons $\left(\chi^{2}=22.56, \mathrm{df}=6, \mathrm{p}<0.01\right)($ Table 3,4$)$.

When referred to actual activity experience in 8 out of 11 items, there were significantly more responses that pointed to the presence of activity experience in the group with high interest in indirect support (Table 5).

\section{DISCUSSION}

First of all, accounting for disparities in the degree of interest for indirect support among distinct occupations. The reason why PT were more aware of direct support, whereas ST were more aware of indirect ones was that PT naturally needed, in their work, to approach physical function directly, and the same reasoning applies to local activities that stem from the respective fields of PT and ST. In other words, it is suggested that there was a tendency for a PT to be involved in the direct improvement of the physical function of their patients exercise and gymnastics.

In conformity with this, Obuchi ${ }^{16)}$ pointed out that micro effects of rehabilitation activities (on each individual) are deeply familiar to PT due to their daily tasks, yet the macro effects (regional effects of urban development for preventive care) are more unfamiliar to them, which is substantiated by our results.

On another note, it is inferred that the ST tended to choose the activities from the viewpoint of indirect support, namely consultation correspondence and technical guidance ${ }^{17}$ ), as a result of their different nature of approach to physical function in

Table 2. Comparison between groups with attributes and historical information

\begin{tabular}{|c|c|c|c|c|c|}
\hline & $\begin{array}{c}\begin{array}{c}\text { Interested in } \\
\text { indirect support } \\
\mathrm{n}=97\end{array} \\
\end{array}$ & $\begin{array}{c}\text { Interested in } \\
\text { direct support } \\
n=51\end{array}$ & $\begin{array}{l}\text { Interested in both } \\
\text { direct and indirect } \\
\text { support } n=206\end{array}$ & $\mathrm{~N} / \mathrm{A}$ & $\mathrm{p}$-value \\
\hline Age (years) ${ }^{a)}$ & $39.2 \pm 8.8$ & $33.2 \pm 7.6$ & $33.3 \pm 7.5$ & & $* *$ \\
\hline Years of experience ${ }^{a)}$ & $13.1 \pm 7.5$ & $8.5 \pm 6.4$ & $9.7 \pm 6.4$ & & $* *$ \\
\hline \multicolumn{6}{|l|}{ Gender $^{\mathrm{b})}$} \\
\hline Male & $51(52.6)$ & $39(76.5)$ & $129(62.6)$ & 0 & $*$ \\
\hline Female & $46(47.4)$ & $12(23.5)$ & $77(37.4)$ & & \\
\hline \multicolumn{6}{|l|}{ Types of rehabilitation professions ${ }^{\text {b) }}$} \\
\hline PT & $58(59.8)$ & $46(90.2)$ & $156(75.7)$ & 0 & $* *$ \\
\hline OT & $23(23.7)$ & $5(9.8)$ & $38(18.4)$ & & \\
\hline ST & $16(16.5)$ & $0(0.0)$ & $12(5.8)$ & & \\
\hline \multicolumn{6}{|l|}{ Job title ${ }^{\mathrm{b})}$} \\
\hline No job title & $41(42.3)$ & $36(70.6)$ & $132(64.1)$ & 2 & $* *$ \\
\hline Chief, Section chief, Manager, Director, etc. & $53(54.6)$ & $11(21.6)$ & $68(33.0)$ & & \\
\hline Others & $3(3.1)$ & $3(5.9)$ & $5(2.4)$ & & \\
\hline \multicolumn{6}{|c|}{ Experience in changing jobs and changing positions $\mathrm{s}^{\mathrm{b})}$} \\
\hline Yes & $70(72.2)$ & $26(51.0)$ & $124(60.2)$ & 2 & $*$ \\
\hline No & $27(27.8)$ & $25(49.0)$ & $80(38.8)$ & & \\
\hline \multicolumn{6}{|l|}{ Experience in post-graduate training b) } \\
\hline Yes & $56(57.7)$ & $16(31.4)$ & $98(47.6)$ & 0 & $* *$ \\
\hline No & $41(42.3)$ & $35(68.6)$ & $108(52.4)$ & & \\
\hline
\end{tabular}

Mean \pm Standard deviation or number of people (\%). N/A: No Answer.

a): Kruskal-Wallis test, $b): \chi^{2}$ test.

${ }^{*} \mathrm{p}<0.05, * * \mathrm{p}<0.01$. 
their daily work. With eating, swallowing, and the hearing function being the main areas of concern for the ST, which may rely on more indirect methodologies, their way of relating directly with the community is limited.

In retrospection, we considered the association between interest in indirect support and attribute information such as age, occupation, affiliation, historical information, e.g., professional and training history, importance in business, and way of thinking about elderly support. These results can be interpreted in line with the accumulation of clinical experience having expanded the range of interest and having led to an interest in activities that do not intrinsically rely on direct support on a daily basis. Coherently, the number of professional positions will increase and the possibility of replacement will also grow as the age and years of experience increases.

In addition, the activities of rehabilitation professionals in the community are different from the usual contents of business activity, and if skills other than basic work are required ${ }^{12)}$, it is assumed that individual factors other than said attribute information (personal values and insights) will affect the degree of interest in indirect support.

The results of this research underpin "regional collaboration" and "understanding of local resources" as preventive care project elements that should always be attained in the whole scope of what support is. Our insight is that rehabilitation

Table 3. Comparison of groups in rehabilitation work "always carried out"

\begin{tabular}{|c|c|c|c|c|}
\hline Item & $\begin{array}{c}\text { Interested in } \\
\text { indirect support } \\
\mathrm{n}=97\end{array}$ & $\begin{array}{c}\text { Interested in } \\
\text { direct support } \\
n=51\end{array}$ & $\begin{array}{l}\text { Interested in both } \\
\text { direct and indirect } \\
\text { support } n=206\end{array}$ & p-value \\
\hline Acquisition of the latest knowledge and technology & $12(12.4)$ & $8(15.7)$ & $31(15.0)$ & \\
\hline Understanding evidence and guidelines & $10(10.3)$ & $5(9.8)$ & $21(10.2)$ & \\
\hline Implementation of doctor's instructions & $72(74.2)$ & $41(80.4)$ & $156(75.7)$ & \\
\hline Rehabilitation based on the name of the disease & $72(74.2)$ & $38(74.5)$ & $145(70.4)$ & \\
\hline $\begin{array}{l}\text { Consider your area of expertise } \\
\text { (cerebrovascular, respiratory, pediatric, etc.) }\end{array}$ & $41(42.3)$ & $22(43.1)$ & $79(38.3)$ & \\
\hline Check your treatment effectiveness & $47(48.5)$ & $29(56.9)$ & $106(51.5)$ & \\
\hline Understand patient (user) needs & $80(82.5)$ & $36(70.6)$ & $161(78.2)$ & \\
\hline Advice and guidance for patient (user) families & $56(57.7)$ & $20(39.2)$ & $80(38.8)$ & \\
\hline Cooperation with other occupations in hospitals and facilities & $65(67.0)$ & $29(56.9)$ & $130(63.1)$ & \\
\hline Cooperation with other regional entities & $42(43.3)$ & $6(11.8)$ & $55(62.7)$ & $* *$ \\
\hline $\begin{array}{l}\text { Implementation of individual support plans, such as } \\
\text { rehabilitation implementation plans }\end{array}$ & $66(68.0)$ & $35(68.6)$ & $139(67.5)$ & \\
\hline Predicting the future of a patient's (user's) life & $71(73.2)$ & $27(52.9)$ & $125(60.7)$ & \\
\hline $\begin{array}{l}\text { Grasping the characteristics and resources of the } \\
\text { corresponding community }\end{array}$ & $26(26.8)$ & $7(13.7)$ & $36(17.5)$ & * \\
\hline
\end{tabular}

Number of people (\%).

$\chi^{2}$ test. $* \mathrm{p}<0.05,{ }^{* *} \mathrm{p}<0.01$

Table 4. Group-to-group comparisons on the wide range of support and responsibilities and the "very" support for the elderly

\begin{tabular}{|c|c|c|c|c|}
\hline Item & $\begin{array}{c}\text { Interested in } \\
\text { indirect support } \\
\mathrm{n}=97\end{array}$ & $\begin{array}{l}\text { Interested in } \\
\text { direct support } \\
\mathrm{n}=51\end{array}$ & $\begin{array}{l}\text { Interested in both direct } \\
\text { and indirect support } \\
\mathrm{n}=206\end{array}$ & p-value \\
\hline $\begin{array}{l}\text { The scope of "support" is the organization and activities } \\
\text { that support the elderly in the community and the entire } \\
\text { person involved in it }\end{array}$ & 40 (41.2) & $6(11.8)$ & $56(27.2)$ & $* *$ \\
\hline $\begin{array}{l}\text { The scope of "responsibility" is the social activities, } \\
\text { including participation in participation in places of } \\
\text { communication in the area }\end{array}$ & $59(60.8)$ & $25(49.0)$ & $96(46.6)$ & \\
\hline $\begin{array}{l}\text { There is a very troubled experience because there are no } \\
\text { resources such as a place of going in the community-based } \\
\text { salon, etc. }\end{array}$ & $25(25.8)$ & $2(3.9)$ & 38 (18.4) & $* *$ \\
\hline $\begin{array}{l}\text { There is a great interest in the content of care manager } \\
\text { management }\end{array}$ & $61(62.9)$ & $7(13.7)$ & $69(33.5)$ & \\
\hline
\end{tabular}

Number of people (\%).

$\chi^{2}$ test. ${ }^{*} \mathrm{p}<0.05,{ }^{* *} \mathrm{p}<0.01$. 
Table 5. Group comparison of activities related to preventive care projects in "experience of activities"

\begin{tabular}{|c|c|c|c|c|}
\hline Items & $\begin{array}{c}\text { Interested in } \\
\text { indirect support } \\
n=97\end{array}$ & $\begin{array}{l}\text { Interested in } \\
\text { direct support } \\
\quad n=51\end{array}$ & $\begin{array}{l}\text { Interested in both direct } \\
\text { and indirect support } \\
n=206\end{array}$ & p-value \\
\hline Teaching exercise and gymnastics & $56(57.7)$ & $26(51.0)$ & $109(52.9)$ & \\
\hline Lecturer in preventive care classes, health courses, etc. & $53(54.6)$ & $15(29.4)$ & $90(43.7)$ & $* *$ \\
\hline $\begin{array}{l}\text { working as a measuring person at physical fitness } \\
\text { measurement meetings, etc. }\end{array}$ & $44(45.4)$ & $28(54.9)$ & $95(46.1)$ & \\
\hline Implementer of short-term intensive programs & $23(23.7)$ & $10(19.6)$ & $43(20.9)$ & \\
\hline Advising and supporting organizers and leaders in the field & $26(26.8)$ & $3(5.9)$ & $34(16.5)$ & $* *$ \\
\hline Volunteer development activities & $18(18.6)$ & $2(3.9)$ & $16(7.8)$ & $* *$ \\
\hline Promote of mutual activities by local residents & $20(20.6)$ & $2(3.9)$ & $21(10.2)$ & $* *$ \\
\hline Participating in community care meetings & $38(39.2)$ & $9(17.6)$ & $63(30.6)$ & $*$ \\
\hline $\begin{array}{l}\text { Advising and supporting administrative staff and community } \\
\text { comprehensive support center staff }\end{array}$ & $44(45.4)$ & $2(3.9)$ & $45(21.8)$ & $* *$ \\
\hline Advising and supporting care managers & $59(60.8)$ & $14(27.5)$ & $88(42.7)$ & $* *$ \\
\hline $\begin{array}{l}\text { Advising and supporting employees of nursing care } \\
\text { facilities, etc. }\end{array}$ & $50(51.5)$ & $11(21.6)$ & $81(39.3)$ & $* *$ \\
\hline
\end{tabular}

Number of people (\%).

$\chi^{2}$ test. ${ }^{*} \mathrm{p}<0.05, *{ }^{*} \mathrm{p}<0.01$.

professionals who are interested in indirect support have consistently thought of the wide range of perspectives not only to improve the abilities of individual elderly people but also to capture the families, groups, and communities surrounding them as well, as indispensable.

In addition, relative to the correlation between interest in indirect support and actual activity experience in this area, there were seven items associated with indirect support out of eight in which there was a significant difference, which was the experience in indirect support leading to an interest in it. As mentioned earlier, the composition of activities comprehended in indirect support is far unlike the original work approach, and since there are more scarce experience opportunities in the first place, it is inferred that the professional record strongly affected the degree of interest of the individuals.

From another perspective, it is simultaneously difficult to have a strong interest in activities in which professionals have not been involved, and it is suggested that this was strongly reflected in $\mathrm{PT}^{18)}$, who have more practice in direct support of the elderly as the cited guidance for exercise and gymnastics, especially in the class of preventive care programs. In this regard, the motive for such a fact seems to be the request for rehabilitation professionals for elderly support by the implementation subject side of the LTCI (municipalities, who are the insurers of the LTCI), which is biased toward the enhancement of physical function ${ }^{12}$. Aiming to guarantee unbiased support, including approaches to the environment surrounding the elderly, it will be compulsory for municipal personnel to alter the content of still biased requests to the professionals in question.

Since this study has been aimed at rehabilitation professionals working in A Prefecture, Japan, and it being a limited region, there is an obvious drawback to the generalization of conclusions issued herein. In addition, our survey asked questions about direct and indirect support of rehabilitation professionals in preventive care projects, but it is possible that many rehabilitation professionals who are not interested in these activities in the first place declined to answer.

Apart from that, it is necessary to further verify the relationship between regional rehabilitation professionals and municipalities entrusted with projects from a wider angle. While also investigating the consciousness and way of thinking of the latter, and the relationship between the former and the supported persons as well, that is, elderly people living in the targeted area.

Finally, it is necessary to confirm the extent to which indirect support by rehabilitation professionals is effective for preventive care services given that it is difficult to demonstrate, for example, by contrast using indicators such as motor function can adequately show the effectiveness of direct support ${ }^{19)}$. Thus, the mentioned effectiveness is expected to be more clearly revealed in the future through the development of new measures by further investigation.

\section{Conference presentation}

A part of this study was presented at the 7th Academic Conference of the Japanese Society of Community-Physical Therapy.

\section{Conflict of interest}

There are no conflicts of interest to declare. 


\section{ACKNOWLEDGMENT}

We thank the rehabilitation professionals in A Prefecture who cooperated in this study.

\section{REFERENCES}

1) Ministry of Health, Labor and Welfare. Future care prevention. https://www.mhlw.go.jp/file/06-Seisakujouhou-12300000-Roukenkyoku/0000075982.pdf (Accessed Jan. 18, 2020)

2) Mitsubishi UFJ Research \& Consulting: New total project for care prevention/daily living support transition strategy Roadmap for regional development. https://www.murc.jp/sp/1509/houkatsu/houkatsu_02_01_h27.pdf (Accessed Jan. 18, 2020)

3) Ministry of Health, Labor and Welfare. Current status and future role of the public long-term care insurance system. https://www.mhlw.go.jp/content/0000213177.pdf (Accessed Jan. 18, 2020)

4) Ministry of Health, Labor and Welfare. Basic concept of the total project for care prevention/daily living support. https://www.mhlw.go.jp/stf/seisakunitsuite/ bunya/0000192992.html.pdf (Accessed Jan. 18, 2020)

5) Tsuji T: Community development for the realization of long-term care prevention. Jpn J Phys Fit Sports Med, 2019, 68: 337-344 (in Japanese). [CrossRef]

6) Ministry of Health, Labor and Welfare. Study Group on Promotion Measures for General Nursing Care Prevention Projects. Reference material about cooperation measures with other projects of community support projects, effective implementation methods, and ideals. https:/www.mhlw.go.jp/content/12300000/000554405.pdf (Accessed Jan. 18, 2020)

7) Arai T, Obuchi S, Kojima M, et al.: [The evaluation of the relationships between physical factors and effects of exercise intervention on physical functions in community-dwelling older people]. Nippon Ronen Igakkai Zasshi, 2006, 43: 781-788 (in Japanese). [Medline] [CrossRef]

8) Ukawa S, Tamakoshi A, Sakamoto A: [A systematic review of intervention programs for frail elderly people enrolled in the Japanese social long-term care insurance system]. Nippon Koshu Eisei Zasshi, 2015, 62: 3-19 (in Japanese). [Medline]

9) Yoshida T, Hattori S: Economic evaluation of Neyagawa City’s long-term care prevention measures by randomized trials. Hou to Keizai 17th National Convention, 2019, 1-9 (in Japanese).

10) Japan Public Health Association, Japan Physical Therapist Association, Japan Occupational Therapist Association: 2015 Community Health Comprehensive Promotion Project. Promotion of community health activities of physical therapists and occupational therapists belonging to local governments and understanding of the actual situation. http://www.japanpt.or.jp/upload/japanpt/obj/files/chosa/suishinjigyou_houkokusho_h27.pdf (Accessed Jan. 18, 2020)

11) Tanaka Y: Collaboration with municipalities: The role that rehabilitation professionals should play from the perspective of the Chiba Regional Rehabilitation Partner System. Sogo Rehabil, 2018, 46: 1189-1195.

12) Japan Rehabilitation Hospitals and Facilities Association: 2018 Geriatric Health Business Promotion Expenses Subsidy Geriatric Health Promotion Project "Survey Research Aiming to Promote Utilization of Rehabilitation in the Community". https://www.rehakyoh.jp/wp/wp-content/uploads/2019/03/rp_ rouken2018_1.pdf(Accessed Jan. 18, 2020)

13) Tanaka Y, Shimizu J: Role of PT / OT in community-based integrated care system-learning from individual community care meetings/long-term care prevention. Tokyo: Bunkodo Press, 2016, pp 184-187.

14) Japan Public Health Association, Japan Physical Therapist Association, Japan Occupational Therapist Association: 2016 Community Health Comprehensive Promotion Project "Activity Promotion Project for Physical Therapists and Occupational Therapists Belonging to Local Governments"-building an information network and creating an activity manual for physical therapists and occupational therapists to promote community health activities smoothly-. http:// www.japanpt.or.jp/upload/japanpt/obj/files/chosa /2016_houkokusyo(syuusei).pdf (Accessed Jan. 18, 2020)

15) Japan Rehabilitation Hospital/ Facility Association, Japan Physical Therapist Association, Japan Occupational Therapist Association, Japan Speech Therapist Association: Guideline for training. https://www.rehakyoh.jp/images/pdf/rp_ikusei2015.pdf (Accessed Nov. 30, 2020)

16) Obuchi S: Town planning for long-term care prevention. J Phys Ther Jpn, 2014, 41: 462-468 (in Japanese).

17) Ministry of Health, Labor and Welfare. "Participation in care prevention for speech therapists". https://www.mhlw.go.jp/content/12300000/000558715.pdf (Accessed Nov. 30, 2020)

18) Ministry of Health, Labor and Welfare. Survey results on the implementation status (2018 implementation) of the 2018 long-term care prevention/daily life support comprehensive project (community support project). https://www.mhlw.go.jp/stf/seisakunitsuite/bunya/0000141576_00006.html (Accessed Jan. 10, 2021)

19) Itou K, Obuchi S, Tsuji I: How effectively does exercise for the elderly work in preventing frailty? Using propensity score matching methods to evaluate the effectiveness of exercise programs aimed at improvement of physical capabilities of the potential frail elderly persons. Journal of Health Care and Society, 2011, 21: 265-281 (in Japanese). 